\title{
IDÉIAS
}

\section{Propõe-se licitação por preços válidos}

Oswaldo Alves de Mattos (*)

A expressão que titula este trabalho, visualizada friamente, notadamente por pessoas não familiarizadas com processos licitatórios, induz a uma interrogação precedida de uma interpretação errônea de que se estaria advogando uma impropriedade, já que nas licitaçōes, buscam-se, exata e unicamente, preços que sejam válidos.

Ocorre, no entanto, que essa expressão nos pareceu a mais adequada, para se constituir em tipo de licitação, para obtenção de preços válidos em determinado periodo, durante - qual a administração, caso ocorra a necessidade, se suprirá mediante requisição ao adjudicatário vencedor da licitação.

A expressão não é, pois, assim, tão infausta. Até pelo contrário, ao final deste trabalho, verificaremos que ela é, no encadeamento dos problemas que surgem a todo instante, uma soluçảo bem recomendável, para que a administração atue de forma preventiva e impeditiva de práticas que geram criticas, crimes contra a $\mathrm{Fa}$ zenda e gastos desnecessários, com utilização de recursos orçamentários que, no fundo, não atendem a nenhuma necessidade pública, efetiva e manifesta.

O procedimento foi adotado na Administração do Municipio do Rio de Janeiro, cujas normas de administração financeira foram elaboradas com a nossa despretensiosa, mas dedicada colaboração, ao tempo em que, honrosamente, nos confiaram o exercício do Cargo de Inspetor Geral

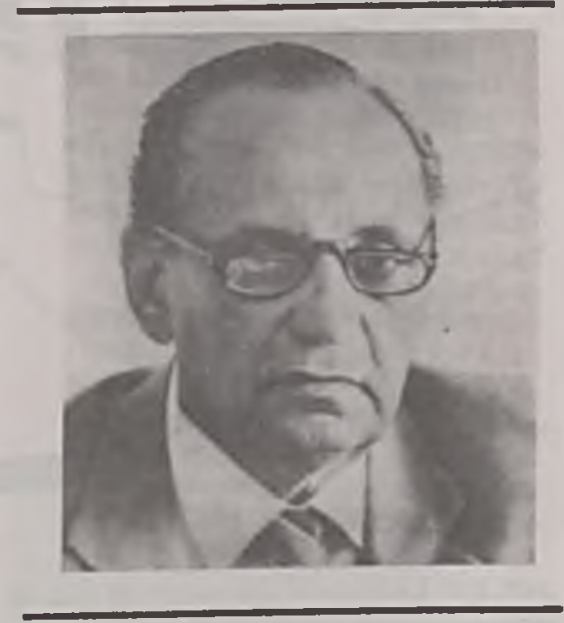

de Finanças. Naquela oportunidade enfrentavamos um desafio. $O$ Poder Revolucionário, de então, fundiu os antigos Estados da Guanabara e do Rio de Janeiro e, conseqüentemente, criou o Municipio do Rio de Janeiro, como Capital do novo Estado. Coube àqueles que mereceram ocupar cargos de direção, criar as estruturas organizacionais e dar-lhes funcionalidade. Quase tudo se devia criar, com a obrigação de em 15 de março de 1975, o Municipio estar funcionando, sem solução de continuidade, na prestação de serviço à população. E isso aconteceu, em que pese a dificuldade de diálogo entre a equipe interventora (Estado) e a equipe obstinada, patriótica e desafiada, que deveria montar aquele Municipio-estado.

E bem verdade que muitos servidores dos 2: e 3\% escalōes do Estado, nossos velhos companheiros de ad-

(*) Auditor Jurídico da FUNCEP, ex-Inspetor Geral de Finanças da Prefeitura do Rio de Janeiro, onde colocouæem prática o método de licitaçðes por preços válidos. ministraçāo pública, sensibilizaramse e abriram as portas de sua colaboração efetiva. E graças a isso, e ao espirito público que acabou por prevalecer, o Municipio nasceu dinàmi$c o$, herdeiro de uma cultura regional aprimorada. Entretanto, pouco alimentado financeiramente. Sucedeu em território do extinto Estado da Guanabara e nele os serviços públicos instalados que deveriam prosseguir e serem dinamizados. Outrora, com toda a receita do ICM e recursos federais transferidos. Dai em diante com uma pequena parcela de $12 \%$, aproximadamente, dessa receita.

Nesse clima, de necessidade de adoçảo de medidas de contenção de despesas, dentre as muitas que se sugeriu, aflorou o agora discutido e comentado tipo de licitação por preços válidos em determinado periodo:

Dec. $3.221 / 81$

"Art. 390.

\$"4:-As licitacóes para fornecimento de materiais ou equipamentos realizadas sob a modalidade de tomada de preços ou convite, respeitados os respectivos limites, poderāo admitir:

1 - proposta de preços unitários considerados válidos para o periodo de 90 (noventa) dias contado da data da adjudicação, durante o qual prevalecerão, a juizo da Administracâo, para atender ás requisiçōes que se tornarem necessárias ao serviço público."

Nota-se que tal procedimento foi adotado em época em que a instabilidade de preços dificultava o licitante, mesmo assim, conseguiu-se bom indice de atendimento. 
Tão importante é esse procedimento para a administração pública, que defendemos até a hipótese de, mesmo em periodo de inflação constante, adotar-se uma regra de cálculo de valores compensatórios. $\mathrm{E}$ mais ainda, que esses preços unitários fiquem condicionados a indices de variação de preços constante de tabela oficial baixada pelo Govemo Federal.

Veja-se que a flexibilidade que tenha de se admitir é recompensada pelo fato de não necessitarmos de dispor, de imediato, de recursos orçamentários e financeiros, definidos em função de quantidades fixadas para um consumo imaginário e em muitos casos descabido.

O que nos induzia a esse procedimento? Logicamente:

10) a licitação não estabelecia comprometimento de despesa imediata;

2:) as requisições ao adjudicatário vencedor da licitação ocorreriam somente ante a necessidade de consumo imediato ou de recomposição de estoque rotativo de consumo previsto para 30,40 ou 60 dias.

Com essa medida, que ora nós ousamos recomendar aos Orgãos Públicos em geral, tem-se como reflexos, ainda:

a) não há necessidade de estocar produtos que não sejam consumiveis por necessidade ocorrente.

b) os almoxarifados ao invés de ficarem abarrotados, se transferem para os próprios fornecedores, que assumem o risco da ociosidade, imprestabilidade e desuso.

c) os Órgåos de Auditoria, tanto interna, como externa, têm condiçòes mais eficazes de fiscalizarem a gestão, pois os almoxarifados não poderão conter produtos, cujo consumo não seja rotineiro.

d) nada se deve comprar, que uma necessidade pública de atendimento nāo dite a ordem.

Com isso evitar-se-ia o que ainda hoje, tristemente, ouvimos da boca de pessoas não bem intencionadas: que fulano e beltrano recebem comissão sobre as compras que fazem; que o almoxarifado do Órgão tal tem material para o consumo até o ano 2000; que o gestor utilizou o saldo da dotação na compra de materiais desnecessários só para não sobrar orçamento. $\mathrm{E}$ por ai outras alegaçỏes, tão infeli-

\section{IDÉIAS}

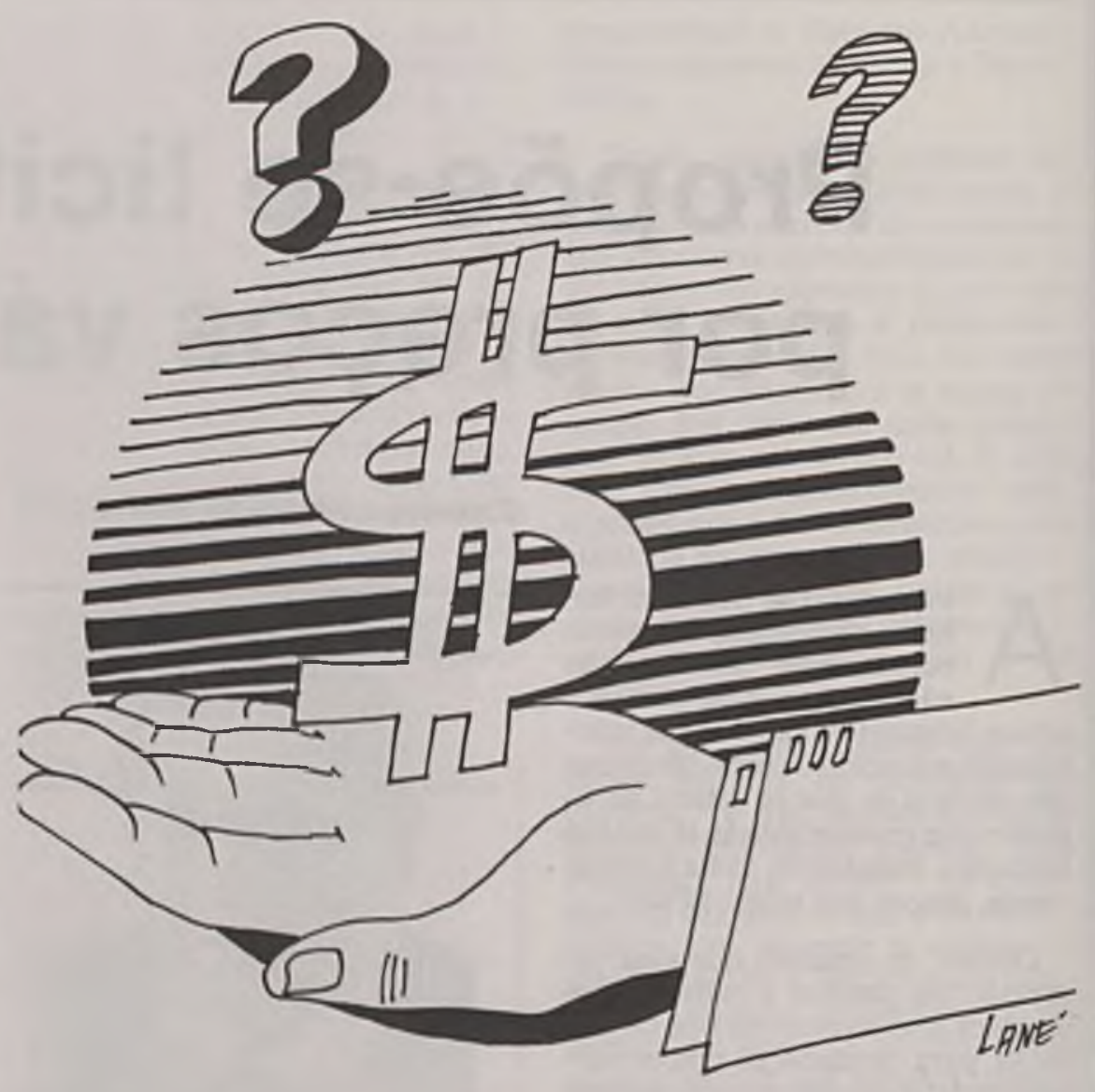

zes, que todos nós gostariamos que os procedimentos da Reforma Administrativa viessem, como esperamos que venham, a banir de nossa sociedade.

Advogamos e insistimos nesse procedimento porque entendemos e estamos convictos de que, mesmo as grandes centrais de materiais, como

por exemplo: as de medicamento, podem repensar seus procedimentos e estabelecer critérios de utilização para a quase totalidade dos bens de consumo rotineiro evitando, com isso, que os remédios percam a validade nos almoxarifados do serviço público. Que isso ocorra nos laboratórios e farmácias!

A propósito, essa recomendação, consta das sugestōes apresentadas pelo Grupo de Trabalho, criado na SEDAP/PR e coordenado pelo titular da CISET daquela Secretaria, do qual, honrosamente fizemos parte, para regulamentação do recém-criado Decreto-Lei n: 2.300, de 21 de novembro de 1986.

Como aquele trabalho possivelmente não alcance divulgação, no nivel de penetração que a Revista do Serviço Público editada pela FUNCEP, hoje oferece, é que nos propusemos a estes breves comentários, já que as entidades da Administração Indireta, exceto as autarquias, deverão editar normas próprias (artigos 86 do diploma citado) e, quem sabe, aproveitem se é que tem valor esta despretensiosa experiência. 